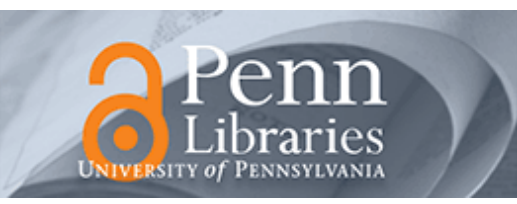

University of Pennsylvania

ScholarlyCommons

8-12-2004

\title{
Public-Access Defibrillation and Survival After Out-of-Hospital Cardiac Arrest
}

\author{
Alfred P. Hallstrom \\ Joseph P. Ornato \\ Myron L. Weisfeldt \\ Andrew H. Travers \\ James Christenson
}

See next page for additional authors

Follow this and additional works at: https://repository.upenn.edu/nrs

Part of the Cardiology Commons, Critical Care Commons, and the Critical Care Nursing Commons

\section{Recommended Citation \\ Hallstrom, A. P., Ornato, J. P., Weisfeldt, M. L., Travers, A. H., Christenson, J., McBurnie, M., Zalenski, R. J., Becker, L. B., Schron, E. B., Proschan, M. A., The Public Access Defibrillation Trial Investigators, \& Riegel, B. (2004). Public-Access Defibrillation and Survival After Out-of-Hospital Cardiac Arrest. The New England Journal of Medicine, 351 (7), 637-646. http://dx.doi.org/10.1056/NEJMoa040566}

Barbara Riegel is not listed as an individual author on this paper but is part of the Public Access Defibrillation Trial Investigators. A full list of Public Access Defibrillation Trial Investigators members for this paper can be found in the Appendix.

This paper is posted at ScholarlyCommons. https://repository.upenn.edu/nrs/57

For more information, please contact repository@pobox.upenn.edu. 


\title{
Public-Access Defibrillation and Survival After Out-of-Hospital Cardiac Arrest
}

\author{
Abstract \\ Background
}

The rate of survival after out-of-hospital cardiac arrest is low. It is not known whether this rate will increase if laypersons are trained to attempt defibrillation with the use of automated external defibrillators (AEDs).

\section{Methods}

We conducted a prospective, community-based, multicenter clinical trial in which we randomly assigned community units (e.g., shopping malls and apartment complexes) to a structured and monitored emergency-response system involving lay volunteers trained in cardiopulmonary resuscitation (CPR) alone or in CPR and the use of AEDs. The primary outcome was survival to hospital discharge.

\section{Results}

More than 19,000 volunteer responders from 993 community units in 24 North American regions participated. The two study groups had similar unit and volunteer characteristics. Patients with treated out-of-hospital cardiac arrest in the two groups were similar in age (mean, 69.8 years), proportion of men (67 percent), rate of cardiac arrest in a public location (70 percent), and rate of witnessed cardiac arrest (72 percent). No inappropriate shocks were delivered. There were more survivors to hospital discharge in the units assigned to have volunteers trained in CPR plus the use of AEDs (30 survivors among 128 arrests) than there were in the units assigned to have volunteers trained only in CPR (15 among 107; $\mathrm{P}=0.03$; relative risk, 2.0; 95 percent confidence interval, 1.07 to 3.77 ); there were only 2 survivors in residential complexes. Functional status at hospital discharge did not differ between the two groups.

\section{Conclusions}

Training and equipping volunteers to attempt early defibrillation within a structured response system can increase the number of survivors to hospital discharge after out-of-hospital cardiac arrest in public locations. Trained laypersons can use AEDs safely and effectively.

\section{Disciplines}

Cardiology | Critical Care | Critical Care Nursing

\section{Comments}

Barbara Riegel is not listed as an individual author on this paper but is part of the Public Access Defibrillation Trial Investigators. A full list of Public Access Defibrillation Trial Investigators members for this paper can be found in the Appendix.

\section{Author(s)}

Alfred P. Hallstrom, Joseph P. Ornato, Myron L. Weisfeldt, Andrew H. Travers, James Christenson, Mary Ann McBurnie, Robert J. Zalenski, Lance B. Becker, Eleanor B. Schron, Michael A. Proschan, The Public Access Defibrillation Trial Investigators, and Barbara Riegel 


\section{The NEW ENGLAND JOURNAL of MEDICINE}

ESTABLISHED IN 1812

AUGUST 12, 2004

VOL. 351 NO. 7

\section{Public-Access Defibrillation and Survival after Out-of-Hospital Cardiac Arrest}

The Public Access Defibrillation Trial Investigators*

\section{ABSTRACT}

\section{BACKGROUN D}

The rate of survival after out-of-hospital cardiac arrest is low. It is not known whether this rate will increase if laypersons are trained to attempt defibrillation with the use of automated external defibrillators (AEDs).

\section{METHODS}

We conducted a prospective, community-based, multicenter clinical trial in which we randomly assigned community units (e.g., shopping malls and apartment complexes) to a structured and monitored emergency-response system involving lay volunteers trained in cardiopulmonary resuscitation (CPR) alone or in CPR and the use of AEDs. The primary outcome was survival to hospital discharge.

\section{RESULTS}

More than 19,000 volunteer responders from 993 community units in 24 North American regions participated. The two study groups had similar unit and volunteer characteristics. Patients with treated out-of-hospital cardiac arrest in the two groups were similar in age (mean, 69.8 years ), proportion of men (67 percent), rate of cardiac arrest in a public location ( 70 percent), and rate of witnessed cardiac arrest ( 72 percent). No inappropriate shocks were delivered. There were more survivors to hospital discharge in the units assigned to have volunteers trained in CPR plus the use of AEDs (30 survivors among 128 arrests) than there were in the units assigned to have volunteers trained only in CPR (15 among 107; $\mathrm{P}=0.03$; relative risk, 2.0; 95 percent confidence interval, 1.07 to 3.77); there were only 2 survivors in residential complexes. Functional status at hospital discharge did not differ between the two groups.

\section{CONCLUSIONS}

Training and equipping volunteers to attempt early defibrillation within a structured response system can increase the number of survivors to hospital discharge after outof-hospital cardiac arrest in public locations. Trained laypersons can use AEDs safely and effectively.
Alfred Hallstrom, Ph.D. (University of Washington, Seattle), and Joseph P. Ornato, M.D. (Virginia Commonwealth University Medical Center, Richmond), assume responsibility for the content of this article. Address reprint requests to the Public Access Defibrillation Clinical Trial Center, University of Washington, School of Public Health and Community Medicine, Department of Biostatistics, 1107 NE 45th St., Room 505, Seattle, WA 98105, or at padctc@u.washington.edu.

*The investigators and coordinators participating in the Public Access Defibrillation (PAD) Trial are listed in the Appendix.

N Engl J Med 2004;351:637-46.

Copyright (c) 2004 Massachusetts Medical Society. 
S UDDEN OUT-OF-HOSPITAL CARDIAC ARrest is a leading cause of death and disability and a leading source of health care costs in the United States. ${ }^{1,2}$ When out-of-hospital cardiac arrest is caused by ventricular fibrillation, defibrillation is an effective treatment; however, its effectiveness diminishes with each passing minute. ${ }^{3,4} \mathrm{Au}-$ tomated external defibrillators (AEDs) are safe and effective when used by trained public-safety personnel who have a duty to respond to medical emergencies. ${ }^{5-10}$ However, it is unclear whether trained volunteer laypersons who do not have a duty to act could save additional lives by using AEDs in addition to cardiopulmonary resuscitation (CPR) in patients who have had an out-of-hospital cardiac arrest.

In this study, we sought to determine whether the use of AEDs by response teams composed of volunteer laypersons trained in CPR would increase the number of survivors to hospital discharge among patients with out-of-hospital cardiac arrest due to cardiac causes.

\section{METHODS}

The Public Access Defibrillation (PAD) Trial was a community-based, prospective, randomized trial conducted from July 2000 through September 2003. In this trial, the number of patients who survived to hospital discharge after out-of-hospital cardiac arrest at a community facility where trained volunteers were able to recognize the event, telephone 911, and perform CPR was compared with the number of patients who survived to hospital discharge after out-of-hospital cardiac arrest at a community facility where volunteers could also provide early defibrillation with an on-site AED. An independent data and safety monitoring board, appointed by the National Heart, Lung, and Blood Institute, monitored patient safety, adverse events, and the conduct of the study. Details of the study design and methods have been described previously. ${ }^{11}$

STUDY CENTERS AND PARTICIPATING FACILITIES The protocol was approved by the institutional review boards at 21 research centers in the United States and 3 in Canada. A diverse sample of community facilities (e.g., shopping malls, recreation centers, hotels, and apartment complexes) was recruited to participate. The facilities had to have a pool of potential volunteer responders and the ability to deliver an AED within three minutes to a person having a cardiac arrest. Facilities having on-site personnel with a duty to respond to medical emergencies (e.g., law-enforcement officers, firefighters, nurses, and physicians) and facilities with existing AED programs were excluded. Communitywide police programs involving the use of AEDs were permitted. Physical facilities were eligible for randomization as a community unit, either singly or in groups, if they could expect at least one out-of-hospital cardiac arrest during the study period (specifically, if the equivalent of at least 250 adults more than 50 years of age were present for 16 hours a day or if the facilities had a history of at least one witnessed out-of-hospital cardiac arrest every two years, on average). Eighty-three percent of the community units were single facilities. Eligible units were required to have clearly defined geographic boundaries and a typical emergency-medical-services system response time to defibrillation of 3 to 15 minutes.

\section{STUDY POPULATIONS}

Two populations with prespecified characteristics were studied: volunteer responders and patients having out-of-hospital cardiac arrest.

\section{Patients}

Because of the nature of out-of-hospital cardiac arrest, the patients were unable to give their consent before receiving the study treatment. Thus, the study was conducted under the regulations governing exceptions to informed consent for emergency research. ${ }^{12}$ Written informed consent was obtained either from the patient or from a family member for the follow-up of survivors.

The primary patient population consisted of persons at least eight years of age with out-of-hospital cardiac arrest from cardiac causes. Patients with out-of-hospital cardiac arrest due to trauma, drug overdose, or other noncardiac causes were excluded from the primary comparison but not from the evaluation of safety. ${ }^{13}$

\section{Volunteer Responders}

Volunteer responders were laypersons whose primary job descriptions did not include the responsibility to provide medical assistance in emergencies. They gave written, informed consent before participation and were trained to competency according to current American Heart Association guidelines. ${ }^{14}$ Retraining was scheduled to take place after three to six months and at one or more additional times during the course of the study. Additional volun- 
teers were recruited to fill vacancies due to attrition (which typically resulted from job changes).

\section{AED DEVICES}

The AEDs used in the study were approved by the Food and Drug Administration and produced by three manufacturers. All the devices provided voice prompts and had electrocardiographic and soundrecording capabilities. Device checks were scheduled to take place monthly.

\section{STUDY DESIGN}

Eligible community units were randomly assigned to a CPR-only response system or to a CPR-plusAED response system. The randomized groups were stratified according to center and stratified within each center according to location (residential vs. public).

A broad net of events triggered the data-collection process. Among the triggering events were syncope, seizure, choking, AED activation or electrode attachment not generated by emergency medical services, or dispatch of emergency-medical-services personnel to a unit for an apparently unresponsive person. Volunteers were alerted to events in various ways (e.g., overhead paging and security notification), depending on the facility's response plan. Events were classified as "presumed cardiac arrests" when more than two ventilations or more than five chest compressions were performed, when any defibrillation shock was delivered by volunteers or by emergency-medical-services personnel, or when the unresponsive person was found dead (even if emergency medical services had not been notified).

An events-adjudication committee, blinded with respect to the treatment group, classified all presumed cardiac arrests as one of the following: definite out-of-hospital cardiac arrest (an arrest of cardiac origin with rhythm identification [identification of ventricular fibrillation, ventricular tachycardia, pulseless electrical activity, or asystole] that was treated by emergency-medical-services personnel), probable out-of-hospital cardiac arrest (one in which only CPR was performed by emergency-medical-services personnel and the patient died), uncertain out-of-hospital cardiac arrest (one in which emergency-medical-services personnel provided treatment, there was no shockable rhythm, and the patient survived), or an event other than out-of-hospital cardiac arrest or an out-of-hospital cardiac arrest of noncardiac causes. ${ }^{13}$ The committee re- viewed a masked narrative report of each event, including rhythm strips and notations as appropriate. Sham masking (i.e., blacking out or altering reports to disguise whether emergency medical services or volunteer responders used an AED) was used to obscure the treatment group. ${ }^{15}$

\section{STATISTICAL ANALYSIS}

Traditional survival rates were initially considered a potential primary outcome measure but then rejected. The numerator of a survival rate would be the number of patients who survived to discharge after definite out-of-hospital cardiac arrest. However, it was unclear whether a reliable denominator could be identified. The logical denominator - all episodes of definite out-of-hospital cardiac arrest is subject to both ascertainment bias and classification bias. Ascertainment bias is a consideration because volunteers might be more likely to report an event involving AED use or to respond to an event because of increased confidence based on the availability of an AED or because emergency-medicalservices personnel may be more likely to continue treatment when an AED is already in place; classification bias is a consideration because an early electrocardiogram would more often be available in the CPR-plus-AED group (and rhythm strips are the best means of observing ventricular fibrillation and diagnosing cardiac arrest). These artifacts could result in a falsely low denominator (and hence a falsely high survival rate) for the CPR-only group. Other candidate denominators were also potentially flawed. ${ }^{13}$

Therefore, the prespecified primary outcome chosen was the number of survivors of definite outof-hospital cardiac arrest in each community unit. A secondary outcome was the number of survivors of definite or uncertain out-of-hospital cardiac arrest. The unit of analysis was the community unit, and the primary comparison between treatment groups involved the use of a two-sample, stratified t-test with which the mean number of survivors per unit within strata were compared. With this approach, the comparison of survival rates composed of noncomparable denominators could be avoided.

A secondary analytic approach involved the use of log-linear (Poisson) generalized-linear-model regression, which permitted adjustment for the risk of out-of-hospital cardiac arrest (estimated as the population at risk multiplied by the years of exposure), as well as adjustments for center and unit type. A priori subgroup analyses were specified for 


\begin{tabular}{|c|c|c|c|}
\hline Characteristic & CPR Only & CPR plus AED & $P$ Value \\
\hline \multicolumn{4}{|l|}{ Community units } \\
\hline No. of units & 497 & 496 & \\
\hline Residential — no. (\%) & $80(16.1)$ & $77(15.5)$ & $0.86 \dagger$ \\
\hline Public - no. (\%) & $417(83.9)$ & $419(84.5)$ & \\
\hline No. of facilities & 638 & 622 & \\
\hline Public facilities — no. (\%) & $547(85.7)$ & $527(84.7)$ & \\
\hline Recreational facilities & $146(26.7)$ & $154(29.2)$ & \\
\hline Shopping centers & $149(27.2)$ & $149(28.3)$ & \\
\hline Entertainment complexes & $56(10.2)$ & $55(10.4)$ & \\
\hline Community centers & $34(6.2)$ & $55(10.4)$ & \\
\hline Large office buildings & $56(10.2)$ & $32(6.1)$ & \\
\hline Other (e.g., hotels, factories, transit centers) & $106(19.4)$ & $82(15.6)$ & \\
\hline Noncompliant facilities — no. (\%) & $63(9.9)$ & $33(5.3)$ & $0.003 \dagger$ \\
\hline Crossed over & $34(5.3)$ & $5(0.8)$ & $<0.001 \uparrow$ \\
\hline Never trained & $22(3.4)$ & $25(4.0)$ & $0.66 \dagger$ \\
\hline Trained but not active & $7(1.1)$ & $3(0.5)$ & $0.34 \dagger$ \\
\hline \multicolumn{4}{|l|}{ No. of AEDs per unit } \\
\hline Mean & NA & 3.2 & \\
\hline Range & NA & $0-17$ & \\
\hline \multicolumn{4}{|l|}{ Events } \\
\hline \multicolumn{4}{|l|}{ Expected cardiac arrests - no./unit } \\
\hline Mean & $1.23 \pm 1.19$ & $1.20 \pm 0.91$ & $0.71 \mathbb{\int}$ \\
\hline Range & $0.01-12.88$ & $0.06-7.79$ & \\
\hline Expected cardiac arrests - total no. & 611 & 597 & \\
\hline Observed presumed cardiac arrests — no. & 266 & 260 & 0.0049 \\
\hline Residential units & 169 & 121 & \\
\hline Public units & 97 & 139 & \\
\hline Observed attempted resuscitations — no. & 133 & 162 & 0.269 \\
\hline Residential units & 45 & 39 & \\
\hline Public units & 88 & 123 & \\
\hline
\end{tabular}

residential as compared with public units. Facilities that crossed over or that chose to discontinue participation were followed for events by review of responses from emergency medical services to the facility or by monthly queries to personnel at the facility. All discovered events were included in the analyses on an intention-to-treat basis.

The cerebral performance category at the time of hospital discharge was used to assess the functional outcome of survivors. Comparisons between treatment groups were made with the use of a chisquare test.

The study was designed to have 80 percent power to detect a 2.1-fold difference in the number of survivors between the CPR-only and the CPR-plusAED groups, assuming 7 percent survival in the CPR-only group. One interim analysis was planned, with the interim stopping boundary specified at a $P$ value of less than 0.005 . The P value that was considered to indicate significance overall was 0.05 .

\section{RESULTS}

The study randomly assigned 993 community units. The units were involved in the study a mean $( \pm S D)$ of $21.5 \pm 5.5$ months. The majority of the facilities ( 85 percent) were in public locations, most of which were recreational facilities and shopping centers 


\begin{tabular}{|c|c|c|c|}
\hline Table 1. (Continued.) & & & \\
\hline Characteristic & CPR Only & CPR plus AED & $P$ Value \\
\hline \multicolumn{4}{|l|}{ Volunteers } \\
\hline Total no. of volunteers trained & 8361 & 11,015 & \\
\hline Attrition rate - \%/yr & 18.7 & 18.8 & $0.52 \|$ \\
\hline No. per trained unit & & & $<0.001 \S$ \\
\hline Mean & $17.6 \pm 15.3$ & $23.0 \pm 17.3$ & \\
\hline Range & $1-149$ & $1-115$ & \\
\hline Age $-y r$ & & & $0.70 \sqrt{5}$ \\
\hline Mean & $39.8 \pm 9.0$ & $39.6 \pm 9.4$ & \\
\hline Range & $17.3-72.0$ & $19.4-69.1$ & \\
\hline Male sex — \% & & & $0.50 \Omega$ \\
\hline Mean & $55.0 \pm 24.7$ & $56.0 \pm 22.2$ & \\
\hline Range & $0-100$ & $0-100$ & \\
\hline High-school education or less — \% & & & $0.51 \int$ \\
\hline Mean & $31.6 \pm 21.1$ & $30.8 \pm 19.1$ & \\
\hline Range & $0-100$ & $0-100$ & \\
\hline
\end{tabular}

* Plus-minus values are means \pm SD. Because of rounding, not all percentages total 100. NA denotes not applicable. $\dagger$ The $\mathrm{P}$ value was calculated by Fisher's exact chi-square test.

$T$ The expected number of cardiac arrests in a unit was calculated as the expected monthly rate of all out-of-hospital cardiac arrests (on the basis of the population or historical rate in the unit), multiplied by the number of months the unit participated in the trial.

$\int$ The $P$ value was calculated by the t-test with respect to unit-level summary measures.

I The $P$ values are associated with the interaction between treatment group and unit type (residential vs. public). The P value was calculated by adding treatment group and public or residential interaction terms to log-linear (Poisson) generalized-linear-model regression analyses with the use of the natural log of the expected number of cardiac arrests as offset and with adjustments for center, treatment group, and unit type (public or residential).

|| The $\mathrm{P}$ value was calculated by the Kaplan-Meier estimator and log-rank statistics.

(Table 1). Although the proportions of facilities that dropped out were similar in the two groups, more CPR-only facilities than CPR-plus-AED facilities crossed over. The observed numbers of arrests were substantially lower than anticipated from the prerandomization unit-enrollment data; however, the survival rate in the CPR-only units was higher than anticipated. After the interim analysis, information regarding the frequency of cardiac arrests and the survival rate in the CPR-only units was used to extend the data-collection period by six months to maintain the specified power level. A significantly larger number of volunteers participated in units that were randomly assigned to CPR plus AED than in units that were assigned to CPR only.

Table 2 outlines the characteristics of the events. The anticipated reporting bias was observed: the reported event incidence was higher in the CPRplus-AED group than in the CPR-only group ( 2.02 vs. 1.81 events per unit per year), and among the reported events, activation of the volunteer system was more frequent in the CPR-plus-AED group. However, CPR-only residential units reported disproportionately more cardiac arrests $(\mathrm{P}=0.004$ for the treatment-by-location [public vs. residential] interaction) (Table 1). When only cardiac arrests where resuscitation was attempted were considered, the interaction disappeared $(\mathrm{P}=0.26)$. Adverse events were rare and consisted mostly of transient psychological trauma to the volunteers and stolen AEDs. No inappropriate shocks were given. There were 526 presumed cardiac arrests or, on average, 1 presumed cardiac arrest per unit every 3.4 years. After blinded review, only 4 events were classified as probable or uncertain out-of-hospital cardiac arrests, and 235 were classified as definite out-of-hospital cardiac arrests, for a total of 239 events, or 1 per unit every 7.4 years.

Table 3 provides the characteristics of out-ofhospital cardiac arrests of cardiac cause. Treated patients were younger and were more likely to have been treated in a public facility than were those who 


\begin{tabular}{|c|c|c|c|c|}
\hline Characteristic & Total & CPR Only & CPR plus AED & $P$ Value \\
\hline \multicolumn{5}{|l|}{ All events } \\
\hline No. of events & 3413 & 1591 & 1822 & $0.001 \dagger$ \\
\hline Incidence - no./unit/yr & & 1.81 & 2.02 & \\
\hline No. of units with $\geq 1$ events & & 330 & 349 & \\
\hline \multicolumn{5}{|l|}{ Adverse events — no. (\%) } \\
\hline Serious & & $1(0.1)$ & 0 & $0.47 \dagger$ \\
\hline Mild or moderate & & $1(0.1)$ & $6(0.3)$ & $0.13 \leftarrow$ \\
\hline Volunteer system activated — mean $\%$ of events per unit & & $53.2 \pm 42.5$ & $60.9 \pm 40.5$ & $0.02 \sqrt{ }$ \\
\hline \multicolumn{5}{|l|}{ Patients } \\
\hline Age $-y r$ & & & & $0.16 \mathbb{\int}$ \\
\hline Mean of unit means & & $52.6 \pm 18.6$ & $54.7 \pm 18.7$ & \\
\hline Range & & $12-100$ & $8-95$ & \\
\hline Male sex — \% & & & & $0.99 \sqrt{\pi}$ \\
\hline Mean per unit & & $50.7 \pm 35.5$ & $50.8 \pm 35.8$ & \\
\hline Range & & $0-100$ & $0-100$ & \\
\hline \multicolumn{5}{|l|}{ Presumed out-of-hospital cardiac arrest } \\
\hline Total - no. & 526 & 266 & 260 & $0.59 \dagger$ \\
\hline Dead on arrival (no EMS treatment) - no. & 231 & 133 & 98 & $0.04 \uparrow$ \\
\hline With do-not-attempt-resuscitation orders & 49 & 26 & 23 & \\
\hline Without do-not-attempt-resuscitation orders & 182 & 107 & 75 & \\
\hline Cardiac cause & 148 & 86 & 62 & \\
\hline Noncardiac cause & 32 & 19 & 13 & \\
\hline Unknown cause & 2 & 2 & 0 & \\
\hline Other event or an arrest of noncardiac cause - no. & 56 & 24 & 32 & $0.22 \dagger$ \\
\hline Arrest of noncardiac cause treated by bystander CPR only 9 & 18 & 8 & 10 & \\
\hline Respiratory arrest treated by EMS $\|$ & 17 & 6 & 11 & \\
\hline Arrest of noncardiac cause treated by EMS $* * *$ & 21 & 10 & 11 & \\
\hline Treated arrest of cardiac cause - no. & 239 & 109 & 130 & $0.09 \dagger$ \\
\hline Probable or uncertain & 4 & 2 & 2 & \\
\hline Definite & 235 & 107 & 128 & \\
\hline \multicolumn{5}{|c|}{$\begin{array}{l}\text { Plus-minus values are means } \pm \text { SD. EMS denotes emergency medical services. } \\
\text { The } P \text { value was calculated by log-linear (Poisson) generalized-linear-model regression at the unit level, with adjust- } \\
\text { ments for the natural log of the expected number of cardiac arrests, the center, and the location (residential vs. public). } \\
\text { The } P \text { value was calculated by Fisher's exact chi-square test. } \\
\text { The } P \text { value was calculated by the t-test with respect to unit-level summary measures. } \\
\text { Ventilations or compressions were given only by bystanders and not by EMS personnel. } \\
\text { Ventilations with or without intubation, but no cardiac compressions, were given. } \\
\text { Among the causes of arrest were drowning, suicide, drug overdose, trauma, choking, and cerebrovascular accident. }\end{array}$} \\
\hline
\end{tabular}

were dead on arrival. Table 4 provides the character- two groups. Shocks were delivered with a publicistics of the events classified as definite out-of-hos- access defibrillator or other non-emergency-medipital cardiac arrests, according to treatment group. cal-services defibrillator in 34.4 percent of the defiThe characteristics of the patients did not differ ac- nite out-of-hospital cardiac arrests (48.4 percent of cording to treatment group. Volunteer-system acti- the events in which a shock was administered) in the vation occurred more frequently in the CPR-plus- CPR-plus-AED group and 1.9 percent in the CPRAED group, but the frequency ofCPR performed by only group. The rate of hospital admission was volunteers or other bystanders was similar in the higher in the CPR-plus-AED group. 
Table 5 provides results with respect to the primary study outcome: survival to hospital discharge. The number of definite out-of-hospital cardiac arrest events was lower in the CPR-only group than in the CPR-plus-AED group (107 vs. $128, \mathrm{P}=0.09$ ). This difference characterized the public units more than it did the residential units. Twice as many patients in the CPR-plus-AED group as in the CPRonly group survived after a definite cardiac arrest, yielding a twofold difference in survival (95 percent confidence interval, 1.07 to $3.77 ; \mathrm{P}=0.03$ ). There was only 1 survivor of definite cardiac arrest in each group in the residential units; when uncertain cardiac arrests were included, the numbers were 31 in the CPR-plus-AED group and 16 in the CPR-only group. There was no difference between the two treatment groups in the cerebral performance category of survivors of definite cardiac arrest; however, it should be noted that the study was not powered to detect small-to-moderate differences in neurologic outcomes.

\section{I SCUSSION}

This study shows that enhancing a well-developed, monitored, layperson-enacted CPR-response plan by adding AEDs and AED training can increase the number of survivors of out-of-hospital cardiac arrest in public locations. This increase in survival does not come at the expense of increased neurologic deficit. In the trial, all volunteers received CPR training; thus, both groups included active interventions. This design tested a strategy of supervised public AED implementation under the condition of an "optimally" trained layperson-enacted response plan and should not be extrapolated to implementation without a response plan. Such extrapolation could underestimate or overestimate the incremental value of AED distribution without a planned response strategy. ${ }^{16,17}$

Choosing the number of survivors as the primary measure provided an arguably unbiased comparison at the cost of a small loss in power ( 2.6 percent) had an unbiased denominator been available. The anticipated bias in obtaining data pertaining to all episodes of out-of-hospital cardiac arrest was observed. After blinded review, there was a clear trend toward an increased frequency of the diagnosis of definite out-of-hospital cardiac arrest in public community units that had been assigned to CPR and AED. The opposite trend, noted in residential units, was probably due to a chance imbalance in unmea-

\begin{tabular}{|c|c|c|}
\hline Characteristic & $\begin{array}{c}\text { Arrest in Persons } \\
\text { Dead on Arrival } \\
\text { without Known } \\
\text { Advance } \\
\text { Directives }\end{array}$ & $\begin{array}{l}\text { Arrest Treated } \\
\text { by EMS }{ }^{\dagger}\end{array}$ \\
\hline \multicolumn{3}{|l|}{ Arrests } \\
\hline No. of events & 148 & 239 \\
\hline Public & 9 & 167 \\
\hline Residential & 139 & 72 \\
\hline $\begin{array}{l}\text { Average interval between arrests } \\
\text { per unit - yr }\end{array}$ & 12.0 & 7.4 \\
\hline Public & 168.9 & 9.1 \\
\hline Residential & 1.8 & 3.5 \\
\hline \multicolumn{3}{|l|}{ No. of events - no. of units } \\
\hline 0 events & 921 & 814 \\
\hline 1 event & 42 & 140 \\
\hline$\geq 2$ events & 30 & 39 \\
\hline Public unit — no./total no. (\%) & $9 / 148(6.1)$ & $167 / 239$ (69.9) \\
\hline $\begin{array}{c}\text { Volunteer system activated - } \\
\text { no./total no. (\%) }\end{array}$ & $40 / 148(27.0)$ & $148 / 238(62.2)$ \\
\hline Witnessed — no./total no. $(\%) \uparrow$ & $4 / 82 \quad(4.9)$ & $136 / 188(72.3)$ \\
\hline Bystander CPR — no./total no. (\%) & $8 / 125(6.4)$ & $143 / 227(63.0)$ \\
\hline \multicolumn{3}{|l|}{ Patients } \\
\hline \multicolumn{3}{|l|}{ Age $-y r$} \\
\hline Mean & $75.7 \pm 13.8$ & $69.8 \pm 15.2$ \\
\hline Range & $35-97$ & $24-100$ \\
\hline Male sex — no./total no. (\%) & $70 / 140(50.0)$ & $160 / 238(67.2)$ \\
\hline White race - no./total no. $(\%) \div$ & $30 / 55 \quad(54.5)$ & $66 / 90 \quad(73.3)$ \\
\hline $\begin{array}{l}\text { Sedentary before arrest - } \\
\text { no./total no. (\%) } \ddagger\end{array}$ & $28 / 34 \quad(82.4)$ & $61 / 177(34.5)$ \\
\hline  & - & $2 / 239(0.8)$ \\
\hline
\end{tabular}

* Plus-minus values are means \pm SD. EMS denotes emergency medical services. $\dagger$ EMS-treated arrests include those classified as definite, probable, or uncertain.

$\$$ This characteristic was determined according to the EMS incident report but frequently had not been recorded.

$\int$ The advance directive was found after the resuscitation attempt.

sured characteristics of the community units; however, the excess cardiac arrests were largely untreatable (i.e., cardiac arrests in patients who were dead on arrival or who had do-not-attempt-resuscitation orders). Therefore, this imbalance probably did not bias the results.

Comparing survivor counts is not a unique approach, but it does differ from the typical method of assessing survival after out-of-hospital cardiac arrest, which generally involves survival rates. The 


\begin{tabular}{|c|c|c|c|}
\hline Characteristic & $\begin{array}{l}\text { CPR Only } \\
\text { (N=107) }\end{array}$ & $\begin{array}{l}\text { CPR plus AED } \\
(\mathrm{N}=128)\end{array}$ & $\begin{array}{c}P \\
\text { Value't }\end{array}$ \\
\hline Volunteer response activated - no. (\%) $\downarrow$ & $57(53.8)$ & $89(69.5)$ & 0.06 \\
\hline Bystander CPR - no. (\%)』 & $62(62.0)$ & $81(64.8)$ & 0.55 \\
\hline $\begin{array}{l}\text { Shock delivered with non-EMS AED } \\
\qquad \text { - no. (\%) }\end{array}$ & $2(1.9)$ & $44(34.4)$ & $<0.001$ \\
\hline $\begin{array}{l}\text { Interval between call to EMS and first } \\
\text { rhythm assessment - } \min ~\end{array}$ & $8.7 \pm 5.5$ & $6.0 \pm 4.7$ & $<0.001$ \\
\hline $\begin{array}{l}\text { Ventricular fibrillation or ventricular tachy- } \\
\text { cardia as first rhythm - no. (\%)\| }\end{array}$ & $43(47.3)$ & $71(57.7)$ & 0.66 \\
\hline $\begin{array}{l}\text { Interval between call to EMS and arrival of } \\
\text { EMS - min }\end{array}$ & $5.6 \pm 3.4$ & $5.7(3.3)$ & 0.63 \\
\hline Patient admitted to hospital - no. (\%) & $29(27.1)$ & $50(39.1)$ & 0.07 \\
\hline
\end{tabular}

* Plus-minus values are means \pm SD. EMS denotes emergency medical services.

$\dagger P$ values were calculated by the t-test with respect to unit-level summary measures.

$\checkmark$ Data were unavailable for one patient in the CPR-only group.

$\int$ Data were unavailable for seven patients in the CPR-only group and three patients in the CPR-plus-AED group.

9 The data shown include those pertaining to non-EMS rhythm identification with an AED. When non-EMS assessments with an AED were excluded, there was no difference between the two groups in the interval between the call to EMS and the first rhythm identification.

$\|$ Data were unavailable for 16 patients in the CPR-only group and 5 patients in the CPR-plus-AED group. The data shown include those pertaining to nonEMS rhythm identification with an AED. When non-EMS assessments with an $A E D$ were excluded, there was no difference between the two groups in the interval between the call to EMS and the first rhythm identification.

comparison of rates among jurisdictions is problematic, because ascertainment of the denominator is very system-sensitive. ${ }^{11}$ Comparing rates within a jurisdiction reduces the problem, although even within a jurisdiction, event ascertainment may change over time. In this trial, it was possible to estimate survival rates that were comparable to those reported by other sources. To do so, we chose denominators that most closely reflected events that would be detected by the average emergency-medical-services system. For comparison with rates reported by emergency medical services with respect to all cardiac arrests, the most reasonable denominator was probably the number of presumed cardiac arrests in the CPR-only group. Similarly, for the comparison with rates reported by emergency medical services with respect to treated cardiac arrests, the number of treated arrests of cardiac cause in the CPR-only group was probably a reasonable denominator. This approach suggests, for the CPR-plusAED group, overall survival rates of 29.9 percent in public locations (since there were 29 survivors of definite cardiac arrest in this group and 97 presumed cardiac arrests in the CPR-only group) and 0.6 percent in the residential complexes ( 1 and 169 , respectively); likewise, it suggests rates of survival after treated cardiac arrest of 40.8 percent in public locations ( 29 and 71 ) and 2.6 percent in residential complexes ( 1 and 38 ), respectively. Though imperfect, these estimates may be useful for comparing the results of this trial with the results of analyses of survival rates in public settings.

Out-of-hospital cardiac arrests were uncommon in the public units; less than half the number expected were reported. This finding emphasizes the difficulty of prospectively identifying locations where out-of-hospital cardiac arrest might occur. The paucity of survivors of out-of-hospital cardiac arrest in large, multiunit, residential locations was striking in both the treatment groups. Although such units represented approximately 16 percent of the study locations and were the site of 28 percent of the cardiac arrests in which resuscitation was attempted, they accounted for less than 5 percent of the survivors of definite out-of-hospital cardiac arrest. Delays in diagnosis and in the mobilization of volunteers at these locations were likely. In these units, volunteers were summoned and responded to potential out-of-hospital cardiac arrests by way of centralized response systems; AEDs were not located in individual households. Thus, the trial was not, by design, a test of AED use in the home.

Our results show that use of AEDs by trained volunteers is safe and effective when initiated in public locations where there is at least a moderate likelihood of a witnessed out-of-hospital cardiac arrest (one every nine years). However, caution must be used when these results are extrapolated to broad, nationwide efforts. The actual effect of widespread implementation of public AED programs on survival after out-of-hospital cardiac arrest in such locations is likely to be moderate overall, since the majority of out-of-hospital cardiac arrests (79 to 84 percent) occur in the home. ${ }^{18,19}$ For example, if widespread implementation of public AED programs resulted in a doubling of survival (such as that seen with this trial), approximately 2000 to 4000 additional lives would be saved each year in the United States. ${ }^{11,18,19}$ However, additional measures are needed to affect the survival of persons who have a cardiac arrest at home.

This trial provides important confirmation that AEDs can be used safely and effectively by trained 
lay responders. Where emergency-medical-services response times are very prolonged (as they may be in rural communities), public-access defibrillation may hold promise for survival after out-of-hospital cardiac arrest. Other than the psychological trauma that affected a few rescuers after a resuscitation attempt, the trial documented no clinically significant harm from the deployment of 1600 AEDs that were accessible to more than 11,000 volunteers in 622 public or residential locations over an average period of 21.5 months. This observation encourages wider use of AEDs.

The study had several limitations. Training programs, emergency-medical-services systems, or hospital care may have varied among the nearly 1000 units, but such heterogeneity should have been equalized by the randomization process. Crossovers were infrequent but were more common in the CPR-only group than in the CPR-plus-AED group. However, the analysis was performed on an intention-to-treat basis. This imbalance in crossovers would be expected to decrease the observed differences between the two groups.

The results of the trial pertain only to the implementation of layperson-based defibrillation systems in public settings with an organized emergencyresponse system in place. Furthermore, the results only apply to locations with a defined window of emergency-medical-services response times (i.e., 3 to 15 minutes). Locations where responses may be delayed (e.g., aircraft, boats, and trains) were excluded because randomization to the CPR-only group would almost completely remove any possibility of defibrillation. Locations with very rapid emergency-medical-services response times were not included because public AED implementation could not be expected to have a large effect in such places.

In public locations, where approximately 20 percent of out-of-hospital cardiac arrests occur, implementing an organized emergency-response plan and training and equipping volunteers to provide early defibrillation with an AED doubled the number of survivors to hospital discharge after out-ofhospital cardiac arrest. The PAD Trial supports the concept that trained volunteers can use AEDs safely and effectively in a variety of public locations.

Supported by a contract (N01-HC-95177) with the National Heart, Lung, and Blood Institute and by the American Heart Association, Guidant Foundation, and Medtronic. AEDs were provided by Cardiac Science Survivalink, Medtronic Physio-Control, and Philips Medical Systems Heartstream. CPR barrier devices were provided by Laerdal Medical.

\begin{tabular}{|c|c|c|c|c|}
\hline \multirow[t]{2}{*}{ Characteristic } & \multirow[t]{2}{*}{$\begin{array}{l}\text { CPR } \\
\text { Only }\end{array}$} & \multirow[t]{2}{*}{$\begin{array}{l}\text { CPR plus } \\
\text { AED }\end{array}$} & \multicolumn{2}{|c|}{ P Value } \\
\hline & & & Unadjusted & Adjusted \\
\hline Definite cardiac arrests - no. & 107 & 128 & $0.09 *$ & \\
\hline Residential units & 37 & 33 & & \\
\hline Public units & 70 & 95 & & \\
\hline Survivors of definite arrest - no. & 15 & 30 & $0.03 \dagger$ & $0.03 *+$ \\
\hline Residential units & 1 & 1 & & \\
\hline Public units & 14 & 29 & & \\
\hline $\begin{array}{l}\text { Survivors of definite or uncertain } \\
\text { arrest }- \text { no. }\end{array}$ & 16 & 31 & & $0.03 *+$ \\
\hline $\begin{array}{c}\text { Cerebral performance category of } \\
\text { survivors of definite arrest } \\
\text { - no. (\%) } \mathbb{}\end{array}$ & & & 0.909 & \\
\hline Normal & $10(71.4)$ & $22(73.3)$ & & \\
\hline Mildly impaired & $3(21.4)$ & $5(16.7)$ & & \\
\hline Moderately impaired & $1(7.1)$ & $3(10.0)$ & & \\
\hline
\end{tabular}

* The P value was calculated by generalized-linear-model (Poisson) regression with the use of the natural log of the expected number of cardiac arrests as offset and with adjustments for center and unit type (public or residential). A treatment-by-location (public or residential) interaction term was not statistically significant for either definite cardiac arrests $(P=0.42)$ or survivors $(\mathrm{P}=0.74)$.

$\dagger$ The groups were stratified according to center and were stratified within center according to location (residential vs. public). The nominal $\mathrm{P}$ value resulting from the stratified, two-sample t-test was adjusted for sequential monitoring by adding 0.005 .

$\mp$ The analysis was adjusted for sequential monitoring.

$\int$ Data were unavailable for 1 of the 15 survivors in the CPR-only group. Patients whose cerebral performance category was considered "normal" were conscious, alert, and able to lead a normal life; they may have had minor psychologic or neurologic deficits, such as mild dysphasia or nonincapacitating hemiparesis. Those whose category was considered "mildly impaired" were conscious and had sufficient cerebral function for part-time work in a sheltered environment or independent activities of daily life; they may have had hemiplegia, seizures, ataxia, dysarthria, dysphasia, or permanent memory or mental changes. Those whose category was considered "moderately impaired" were conscious and had at least limited cognition but were dependent on others for daily support (i.e., in an institution or at home with exceptional family effort); they may have had severe memory disturbances, dementia, or the "locked-in" syndrome.

If The P value was calculated by Pearson's chi-square test.

Dr. Christenson reports having received research support from Medtronic Physio-Control, and Dr. Becker research support from Philips Medical Systems and support from Laerdal Medical.

We are indebted to the participating volunteers and facilities for their sustained commitment to the trial; to the emergency-medicalservices systems serving the participating facilities for their assistance with data collection; to the numerous local organizations that donated personnel and supplies for training volunteers; and to Costas T. Lambrew, M.D., David C. Goff, Jr., M.D., Ph.D., Laurence McCullough, Ph.D., Louis Gonzales, E.M.T.-P., Henry A. Feldman, Ph.D., and Allan Braslow, Ph.D., for serving on the data and safety monitoring board. 
The investigators and coordinators participating in the PAD Trial were as follows: Writing Committee - A.P. Hallstrom, J.P. Ornato, M. Weisfeldt, A. Travers, J. Christenson, M.A. McBurnie, R. Zalenski, L.B. Becker, E.B. Schron, and M. Proschan. Investigators and Coordinators - Arizona Heart Institute, Phoenix: K. Vijayaraghavan, T. Mattioni, and C. Williams. Calgary Emergency Medical Services, Calgary, Alta., Canada: A.R. Anton, C.D. Jones, S. Yahn, and D. Rabel. Christiana Health Care Services, Newark, Del.: R.E. O'Connor, P. McGraw, M. Bollinger, and R.E. Megargel. East Coast Clinical Research,Virginia Beach, Va.: R.A. Craven, L.A. Bosken, M.P. Burke, J. Paulsen, and G. Newton. Hennepin County Medical Center, Minneapolis: B.D. Mahoney, R. Knudson-Ballard, and G. Vasquez. Indiana University, Indianapolis: W.J. Groh, D. Cordes, and S.J. Bondurant. Intermountain Injury Control Research Center, Department of Pediatrics, University of Utah School of Medicine, Salt Lake City: N.C. Mann, B. Shaum, K. Brown, and K. Jacobsen. Medical College of Wisconsin, Milwaukee: T.P. Aufderheide, R.G. Pirrallo, C.J. Conrad, D.J. Kitscha, C.W. Sparks, C. von Briesen, K.A. Deja, M.M. LeStarge, R.W. Janisch, S.S. Schmidt, L. Parmenter, and L. Grabowski. Mission Hospital, Mission Viejo, Calif., and Orange County Emergency Medical Services, Orange County, Calif.: S. Ehrlich, B. Haynes, L. Asbury, and M. Amaya. Mount Sinai School of Medicine, New York: L.D. Richardson, F. Ehlert, C. Freyberg, N. Richmond, C. Shields, I. Wilets, and J. Holohan. Oregon Health and Science University, Portland: M. Daya, M.D. Gunnels, J.R. Hedges, J. Jui, T. Schmidt, L. Wittwer, H. Brooks, C. Burke, and D. Griffiths. Riverside County Emergency Medical Services, Riverside, Calif:: M. Osur, B. MacGavin, and B. Myrin. Institute of Critical Care Medicine, Palm Springs, Calif:: M.H. Weil. Loma Linda University Medical Center, Loma Linda, Calif: R. Sehra. University of Washington, Seattle: R.O. Cummins, A. Doherty, S. Thompson, and S. Wood. St. Paul's Hospital, Vancouver, B.C., Canada: J. Christenson, S. Pennington, A. Holmes, H. Payne, R. Webb, N. Douglas, and P. Lawson. Stony Brook University, Stony Brook, N.Y.: M.C. Henry, S. Johnson, H. Thode, and E.R. Stapleton. SUNY Upstate Medical University Hospital, Syracuse, N.Y.: D.B. Reed, L.H. Brown, and L.M. Evans. George Washington University Medical Center, Washington, D.C.: P.J. Varghese and R. Lucas. University of Alabama at Birmingham, Birmingham: T.E. Terndrup, S. Stephens, S. Nafziger, and J. Sanford. University of Alberta-City of Edmonton Emergency Response Department, Edmonton, Alta., Canada: A. Travers, A. Panylyk, K. Irwin, and B. Heisz. University of Chicago Hospitals, Chicago: L.B. Becker, A. Barry, and E. Demertsidis. University of Cincinnati, Cincinnati: J. Van Zile, C. Grimmelsman, and L. Nolting. University of Pittsburgh School of Medicine, Pittsburgh: V.N. Mosesso, Jr., B.K. Slater, V.J. Campbell, and D. Hostler. Virginia Commonwealth University Health System, Richmond: J.P. Ornato (Steering Committee chair), M.A. Peberdy, J. Overton, and K. Schaffer. Wayne State University, Detroit: R. Zalenski, S. Compton, R. Dunne, R. Swor, R. Welch, L.M. Mango, and K. Bilicki. Johns Hopkins University School of Medicine, Baltimore: M. Weisfeldt. Ohio State University, Columbus: M.R. Sayre. School of Nursing, University of Pennsylvania, Philadelphia: B. Riegel. National Heart, Lung, and Blood Institute, Bethesda, Md.: E.B. Schron, J. Fleg, M.J. Domanski, M. Proschan, Y. Rosenberg, L. O'Neill, and the following former project officers: D. Simons-Morton and M.E. Salive. Economic Center, University of Ottawa, Ottawa, Ont., Canada: G. Nichol, G. Wells, E. Huszti, J. Rokosh, and D. Morris. Harvard University, Boston: K. Kuntz. University of Alberta, Edmonton, Alta., Canada: D. Feeny. Clinical Trial Center, University of Washington, Seattle: A.P. Hallstrom, H.L. Greene, M.A. McBurnie, J. Powell, L. Van Ottingham, A. Birnbaum, R.B. Ledingham, R. Moore, M. Morris, M. Scholz, and A. Kerr.

REFERENCES

1. Rosamond WD, Chambless LE, Folsom AR, et al. Trends in the incidence of myocardial infarction and in mortality due to coronary heart disease, 1987 to 1994 . N Engl J Med 1998;339:861-7.

2. State-specific mortality from sudden cardiac death - United States, 1999. MMWR Morb Mortal Wkly Rep 2002;51: 123-6.

3. Cummins RO, Ornato JP, Thies WH, Pepe PE. Improving survival from sudden cardiac arrest: the "chain of survival" concept: a statement for health professionals from the Advanced Cardiac Life Support Subcommittee and the Emergency Cardiac Care Committee, American Heart Association. Circulation 1991;83:1832-47.

4. Valenzuela TD, Roe DJ, Cretin S, Spaite DW, Larsen MP. Estimating effectiveness of cardiac arrest interventions: a logistic regression survival model. Circulation 1997; 96:3308-13.

5. White RD, Hankins DG, Bugliosi TF. Seven years' experience with early defibrillation by police and paramedics in an emergency medical services system. Resuscitation 1998;39:145-51.

6. Mosesso VN Jr, Davis EA, Auble TE, Par is PM, Yealy DM. Use of automated external defibrillators by police officers for treatment of out-of-hospital cardiac arrest. Ann Emerg Med 1998;32:200-7.

7. Page RL, Joglar JA, Kowal RC, et al. Use of automated external defibrillators by a U.S. airline. N Engl J Med 2000;343:1210-6.

8. Caffrey SL, Willoughby PJ, Pepe PE, Becker LB. Public use of automated external defibrillators. N Engl J Med 2002;347: 1242-7.

9. Valenzuela TD, Roe DJ, Nichol G, Clark LL, Spaite DW, Hardman RG. Outcomes of rapid defibrillation by security officers after cardiac arrest in casinos. N Engl J Med 2000; 343:1206-9.

10. Myerburg RJ, Fenster J, Velez M, et al Impact of community-wide police car deployment of automated external defibrillators on survival from out-of-hospital cardiac arrest. Circulation 2002;106:1058-64.

11. Ornato JP, McBurnie MA, Nichol G, et al. The Public Access Defibrillation (PAD) Trial: study design and rationale. Resuscitation 2003;56:135-47.

12. Mosesso VN Jr, Brown LH, Greene HL, et al. Conducting research using the emergency exception from informed consent: the Public Access Defibrillation (PAD) Trial experience. Resuscitation 2004;61:29-36.

13. Sayre MR, Travers AH, Daya M, et al. Measuring survival rates from sudden cardi- ac arrest: the elusive definition. Resuscitation 2004;62:25-34.

14. Guidelines 2000 for cardiopulmonary resuscitation and emergency cardiovascular care. 4 . The automated external defibrillator: key link in the chain of survival. Circulation 2000;102:Suppl I:I-60-I-76.

15. Antiarrhythmics Versus Implantable Defibrillators (AVID) - rationale, design, and methods. Am J Cardiol 1995;75:470-5.

16. Stiell IG, Wells GA, Field BJ, et al. Improved out-of-hospital cardiac arrest survival through the inexpensive optimization of an existing defibrillation program: OPALS study phase II: Ontario Prehospital Advanced Life Support. JAMA 1999;281:1175-81.

17. Becker LB, Ostrander MP, Barrett J, Kondos GT. Outcome of CPR in a large metropolitan area - where are the survivors? Ann Emerg Med 1991;20:355-61.

18. Becker L, Eisenberg M, Fahrenbruch C, Cobb L. Public locations of cardiac arrest: implications for public access defibrillation. Circulation 1998;97:2106-9.

19. Pell JP, Sirel JM, Marsden AK, Ford I, Walker NL, Cobbe SM. Potential impact of public access defibrillators on survival after out of hospital cardiopulmonary arrest: retrospective cohort study. BMJ 2002;325:515. Copyright (c) 2004 Massachusetts Medical Society. 